\title{
Eco-lógica: Efigênia entre arte e vida
}

\section{Eco-logic: Efigênia between art and life}

Kátia Maria Kasper ${ }^{1}$

Resumo: Este artigo apresenta aspectos de uma pesquisa a propósito dos processos criativos e formativos de Efigênia Rolim, em ressonância com os conceitos de singularização e ecosofia. Eco-lógica voltada para traçados de linhas de fuga, de modo que se escape aos modos padronizados de subjetivação do capitalismo globalizado, à sua tentativa de produção de subjetividade serializada, aos modelos e moldes. Afirmação de outras possibilidades de vida. A lógica da singularização é a lógica das intensidades, cujo modo de operar está próximo daquele do artista. As principais fontes de pesquisa são depoimentos de Efigênia, além de registros fotográficos e produção de documentários de sua atuação e do acervo mantido em sua residência. Do encontro de Efigênia com diversos materiais (vindos de restos da indústria, do comércio, do consumo diário, sonhos, papéis de bala), surgem as histórias e criações. Invenção de uma vida.

Palavras-chave: Ecosofia. Formação. Singularização. Efigênia Rolim. Educação ambiental.

\begin{abstract}
This paper presents aspects of a research project about the creative and formative processes of Efigênia Rolim, in resonance with the concepts of singularization and ecosophy. Eco-logic is oriented to lines of flight, so that one escapes from standardized modes of subjetivation of globalized capitalism, its serialized subjectivity production attempt, models and molds and an affirmation of new life possibilities. The logic of singularization is that of intensities, whose mode of operation is close to that of an artist. The main sources of this research are testimonial of Efigênia, photographic records, and the production of documentaries on her performances and the collection kept in her residence. From encounters of Efigênia with miscellaneous materials (remnants of industry, commerce, daily consumption of waste, dreams, packets of candy) arise stories and creations- the invention of a life.
\end{abstract}

Keywords: Ecosophy. Formation. Singularization. Efigênia Rolim. Environmental education.

\footnotetext{
${ }^{1}$ Setor de Educação, Universidade Federal do Paraná (UFPR), Rua General Carneiro, 460, $5^{\circ}$ andar, Centro, CEP 80060-150, Curitiba, PR, Brasil. E-mail: katiakasper@uol.com.br
} 
Kasper, K. M.

Figura 1. Efigênia Rolim na Feira do Largo da Ordem.

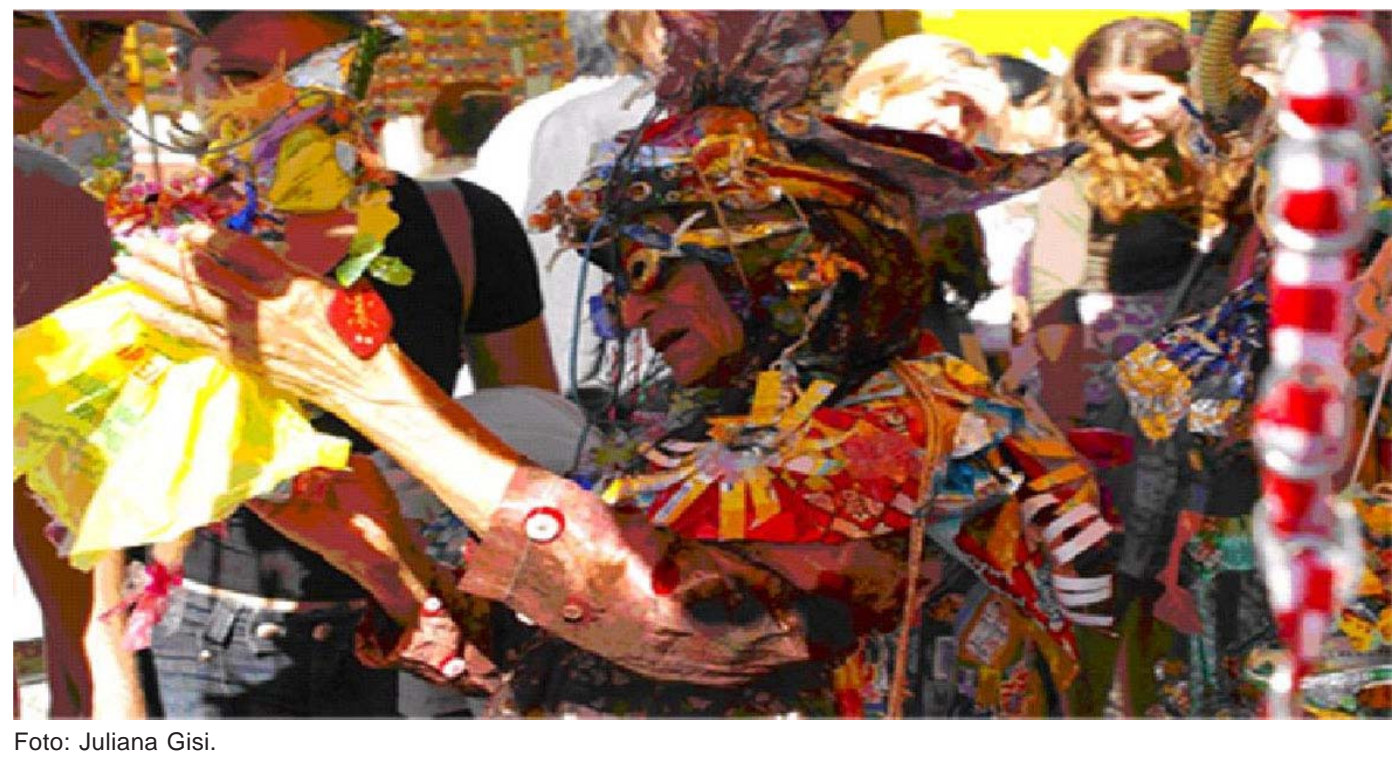

\section{Introdução: uma artista da sucata}

Este artigo apresenta aspectos de uma pesquisa a propósito dos processos criativos e formativos de Efigênia Rolim, em ressonância com os conceitos de singularização e ecosofia. As reverberações produzidas com as áreas de Educação em Ciências e Educação Ambiental nem sempre estão detalhadamente enunciadas, exceto pelos conceitos mencionados acima, que atravessam toda a lógica da escrita do texto e da pesquisa em questão. $\mathrm{O}$ foco desse estudo está mais voltado para os processos do que para o produto. Vale ressaltar que vários são os processos de ensino-aprendizagem abordados nesse trabalho, envolvendo elementos de educação não formal, na afirmação do enlace insolúvel entre educação, subjetividade, ambiente e sociedade. Relação entre educação e produção de outros modos de existência, evidenciando a construção de relações inusitadas entre ambiente, arte e subjetividade.

Acompanhando aspectos da história de vida de Efigênia e o modo como ela se constrói como "artista da sucata" - para utilizarmos os seus termos -, evidenciamos um caso, um processo singular e singularizante de formação que escapa aos modelos instituídos de formação escolar. Tais modelos envolvem também uma distribuição disciplinar de conhecimentos, inclusive no campo das artes. Efigênia atravessa esses campos de modo transversal, construindo experimentalmente um processo de formação marcado pelos encontros com os outros, fora das instituições que organizam os processos formativos. Nesse sentido, encontramos certas ressonâncias entre o modo de abordarmos a formação como um processo de invenção de si e a "formação ecosófica", pensada por Albernaz e Laurino (ALBERNAZ; LAURINO, 2001). 
Efigênia nos ensina de várias formas. Com seus bonecos, contando histórias de como é possível inventar novos modos de existência, como valorizar a vida em todas as suas dimensões, especialmente tratando-a como matéria ética. Seus bonecos contam histórias a respeito de como é possível inventar outros mundos. Seja em sua barraca, na feira de arte e artesanato, seja nas oficinas que acontecem em escolas, nas quais ensina a produzir arte com sucata. Efigênia nos ensina por meio de sua história de vida. Parece operar com o conceito de ecosofia de Félix Guattari (2001). Com Efigênia, aprendemos possibilidades para se pensar o ambiente e a educação em conexão com as artes. A potência das narrativas de Efigênia envolvem, igualmente, adultos e crianças que as escutam. Efigênia desenvolve uma didática da invenção, que escapa dos modelos e moldes. Foge dos modelos tanto no que diz respeito ao "como" e "onde" se deve ensinar, quanto no que se refere aos modos de vida afirmados em tais narrativas. Ela nos ensina a transver o mundo e a criar outros mundos. Afirmação de outros modos de existência - de sentir, agir, pensar, afirmando a potência da invenção, da criação. Eco-lógica.

\section{O encontro com Efigênia na cidade de Curitiba}

Foi perambulando pelas ruas do centro da cidade de Curitiba, em dezembro de 2005, num domingo ensolarado, que conheci Efigênia Ramos Rolim, na feira de antiguidades e artesanato do Largo da Ordem. Não saberia afirmar ao certo o que ela me provocou, mas, imediatamente, comecei a buscar aprender com ela, fazer rizoma com Efigênia. Estava em sua barraca, envolta em uma multiplicidade de cores, com objetos feitos com papéis de bala e outros materiais. Efigênia e seu chapéu, seus óculos, seu manto: instaurando mundos.

Efigênia condensa uma experiência única de produção de si, uma política de subjetivação que conseguiu escapar à loucura, à miséria, ao aprisionamento em qualquer identidade fixa, por meio da criação. Seu processo criativo envolve um agenciamento peculiar, entrelaçando formas plásticas, narrativas e performance. Elementos que compõem a singularidade da sua criação.

Do encontro de Efigênia com os mais diversos materiais, vindos de restos da indústria, do comércio, de lixos do consumo diário, com sonhos, com histórias, seguindo o fluxo do desejo, surgem as criações. Inventando um jeito de viver, criando possibilidades de existência ali onde não se veria nada disso. Cria esculturas, bonecos que contam estórias, as quais se misturam com estórias contadas por Efigênia a respeito de sua própria vida e com narrativas de outros bonecos, em uma polifonia sem fim. Produz objetos, como mantos, chapéus. Também escreve poesias.

Ela nasceu em 1931, no interior de Minas Gerais, em Santo Antônio de Mantipó, município de Abre Campo, "com dois ou três parafusos a menos. Nasceu prematura, muito pequena e fraca, sendo alimentada por um conta-gotas" (TROVÃO, 2000, p. 50) Ana Carolina Trovão, ao estudar a história de vida de Efigênia, ressalta que o conta-gotas é fonte de alimento e é também o "conta-gotas da transformação", que aparece na música que Efigênia cantava aos domingos, na Feira dominical do Largo da Ordem: "transformou morte em vida e gotas em mar". 
Kasper, K. M.

Peguei meu conta-gotas

Comecei a pingar

Pingando uma gota na outra

Foi até formar o mar

Ie... oh... oh

Com o conta-gotas na mão

Mas as gotas foi pingando

E o mar foi aumentando

Fiz uma transformação... (TROVÃO, 2000, p. 49)

O pai e um dos tios de Efigênia eram contadores de história. Ela atribui a essa ascendência o seu gosto por contar histórias. O pai sentava na escada com um violão e cantava:

A uma hora eu nasci. Às duas, me batizei. Às três, eu estava em namoro e às quatro horas me casei. Às cinco, me adoeci e às seis pedi confissão. Às sete, eu em cima da mesa e às oito, dentro de um caixão. Às nove, o acompanhamento. Às dez, na porta da igreja. Às onze, no cemitério. E à meia-noite, no céu... (TROVÃO, 2000, p. 38)

No documentário "O filme da rainha" (2005), ela afirma que com dez, 12 anos de idade, escreveu um livro de poesias. Manuscrito, faltando algumas letras. A mãe "olhou, ficou muito admirada. [...] E ela pegou, jogou esse livro fora. Falou que não entendia porque eu estava escrevendo poesia". Continua essa narrativa, afirmando que "o povo pensa que sou uma pessoa meio maluquinha... Criou dentro da minha alma a poesia" (O FILME..., 2005),

Efigênia mudou-se para Curitiba em 1971, com filhos e marido, buscando um tratamento de saúde para este último, que sofria com problemas cardíacos. Inicialmente, instalaram-se em um albergue, foi muito duro. Houve um momento em que, sem saber para onde ir, ficou na porta da igreja e ganhou esmolas.

\section{Lixo-pérola: a rainha do papel de bala}

Certa vez - bem mais tarde, já viúva e com os filhos crescidos -, encontrou papéis de bala verdes e brilhantes no chão da rua XV de Novembro, no centro de Curitiba. Pensou que fossem pérolas. "Com eles fez uma série de palitinhos e depois enfeitou um pé de chinelo e nele escreveu: "Efigênia: uma artista da sucata, um pé de chinelo"' (TROVÃO, 2000, p. 53). No documentário "O filme da rainha", ela afirmou que, nessa terça-feira de manhã, na rua $\mathrm{XV}$ de Novembro, "começou a minha vida, aqui começou a vida da rainha do papel" (O FILME..., 2005). O papel de bala

[...] brilhou na minha frente e era o momento que deu aquela explosão. Eu pensei que fosse uma jóia. Era muito mais do que fosse uma jóia. Porque se fosse uma jóia ia usufruir e ia terminar a história aqui mesmo. Mas você está dando vida a um mísero caído que perambula pela rua sem recheio. (O FILME..., 2005) 
Eco-lógica: Efigênia entre arte e vida

E concluiu: "Trabalhar com o papel de bala é trabalhar com a minha própria vida. Eu jamais posso perder o meu recheio. O dia que eu perder meu recheio, eu... puf!" (O FILME..., 2005).

Teve início seu trabalho de confecção de objetos com papéis de bala. Em 1990, "começou a expor seus trabalhos e a contar suas histórias na Feirinha de Domingo do Largo da Ordem. Esta feira de arte e artesanato surgiu da unificação da Feira Popular de Curitiba com o Mercado das Pulgas" (TROVÃO, 2000, p. 53).

Dentre os vários encontros que teve em sua vida, aquele com o amigo Hélio Leites foi muito especial. No documentário "O filme da rainha", ela narrou um momento-chave de sua vida: em 1990, enquanto se preparava para ir representar os artesãos curitibanos no México, Hélio disse-lhe que ela era menina, tinha quinze, vinte anos, e era muito bonita. Não era velha, nem feia. Parafraseando Helena Kolody, afirmou que a estrela brilharia para ela essa noite mais do que o sol. Ela começou a sentir uma emoção, uma vertigem. Afirmou que essas palavras do Hélio a curaram. "Naquele momento, eu fui curada de uma coisa muito profunda: se eu sou velha, se eu sou feia, como eu posso entrar no mundo artístico?" (O FILME..., 2005), afirma Efigênia no filme. Ela se considerava velha e feia e pensava que só as pessoas jovens, bonitas e com estudo podiam entrar no mundo artístico. Pensava estar "muito velha pra isso".

Hélio Leites a levou para a feira do Largo da Ordem. Inicialmente, expunha junto com ele e, depois, ganhou sua própria barraca, colorida e enfeitada com bonecos diversos, girafinhas, cavalinhos etc., feitos com papéis de bala e outros materiais...

"A feirinha é onde eu nasci", afirmou Efigênia.

Figura 2. Efigênia Rolim contando histórias.

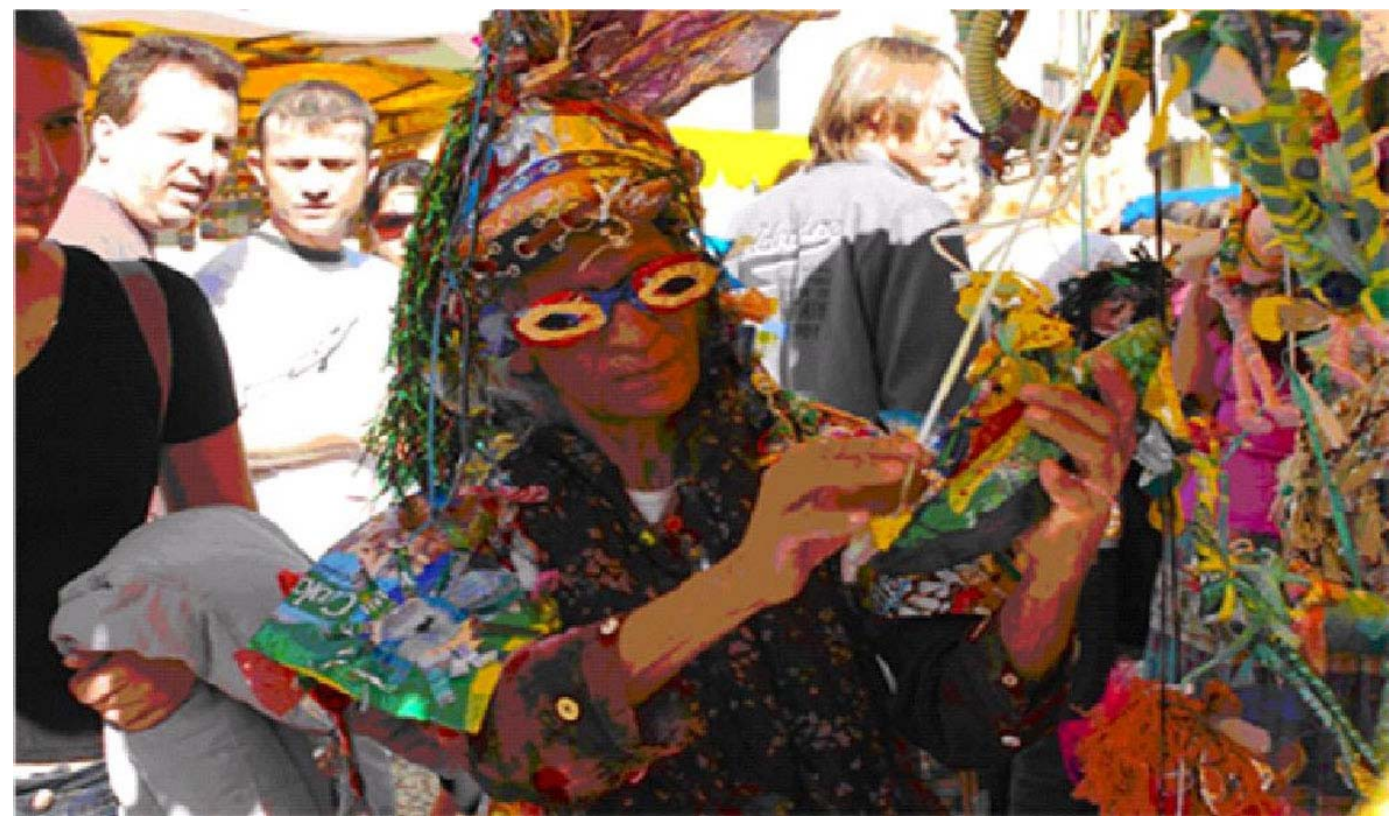

Foto: Juliana Gisi. 
Foi na década de 1990 que seu trabalho começou a ganhar repercussão em alguns locais. Em 1998, participou do programa de entrevistas de Jô Soares, no SBT. Dois documentários foram realizados a propósito de sua vida, um para o canal de televisão GNT e outro por Tion Kin e Estêvão, em Curitiba. "A Rainha da Sucata" é o nome desse documentário, realizado em 1998, premiado em alguns festivais, conforme A. C. R. Trovão (2000).

Em 2005, o mexicano Sérgio Mercúrio dirigiu o documentário "O filme da rainha", a respeito de Efigênia, realizado em Curitiba. Obra vencedora da categoria "Melhor Documentário Estrangeiro" na 31 "Mostra Internacional de Cinema de São Paulo".

Efigênia Rolim trabalha também em projetos com escolas, oferecendo oficinas na temática da sucata e reciclagem. Recebeu alguns prêmios, entre eles o Prêmio de Culturas Populares do Ministério da Cultura, em 2007. No ano seguinte, conquistou a Ordem do Mérito Cultural do Ministério da Cultura. Em 2000, ela participou, em Brasília, de uma exposição comemorativa dos Quinhentos Anos do Brasil.

Atualmente, ela organizou um acervo com suas produções em sua casa, na cidade de Curitiba.

\section{Ecosofia e singularização}

Interessa-nos investigar formas de se escapar ao controle em uma sociedade, modos de resistência ao poder que nos quer conformes - aos padrões, modelos, moldes - inclusive, nos processos de formação e de educação não formal. Para Gilles Deleuze e Félix Guattari (1980), um campo social não se contradiz, mas ele foge, vaza, e isto é primeiro. Uma sociedade se define por seus fluxos de desterritorialização, por suas linhas de fuga. Cabe a cada um de nós inventá-las e, para isso, precisamos traçá-las "efetivamente, na vida" (DELEUZE; GUATTARI, 1980). Ou seja, singularizar, afirmando outros modos de agir, outras sensibilidades, outra percepção etc.

Félix Guattari (2001) pensa as relações entre os três registros ecológicos - o do meio ambiente, o das relações sociais e o da subjetividade humana - através de uma articulação ético-política, que chama de ecosofia. Para o autor, a saída para as crises de nossa época está na articulação da subjetividade "em estado nascente, do socius em estado mutante, do meio ambiente no ponto em que pode ser reinventado" (GUATTARI, 2001, p. 31).

O que está em questão são as maneiras de viver no planeta. Para o autor, a ecosofia social consistirá no desenvolvimento de práticas de reinvenção de maneiras de ser do casal, da família, do contexto urbano, do trabalho etc. Reconstruir as "modalidades do ser-em-grupo". Fazer "funcionar práticas efetivas de experimentações tanto nos níveis microssociais quanto em escalas institucionais maiores" (GUATTARI, 2001, p. 16)

À ecosofia mental caberá reinventar

[...] a relação do sujeito com o corpo, com o fantasma, com o tempo que passa, com os 'mistérios' da vida e da morte. Ela será levada a procurar antídotos para a uniformização midiática e telemática, o conformismo das modas, as manipulações da opinião pela publicidade, pelas sondagens etc. Sua maneira de operar aproximar-se-á mais 
daquela do artista do que a dos profissionais 'psi', sempre assombrados por um ideal caduco de cientificidade. (GUATTARI, 2001, p. 16)

Cabe, também, à nova referência ecosófica, nas escalas individuais e coletivas, "naquilo que concerne tanto à vida cotidiana quanto à reinvenção da democracia - no registro do urbanismo, da criação artística, do esporte etc. -" focar os "dispositivos de produção de subjetividade, indo no sentido da re-singularização individual e/ ou coletiva...” (GUATTARI, 2001, p. 15).

Conforme Guattari (2001), existe uma tendência crescente em relação ao capitalismo pós-industrial, chamado, pelo autor, de Capitalismo Mundial Integrado (CMI), de descentramento de seus focos de poder "das estruturas de produção de bens e de serviços para as estruturas produtoras de signos, de sintaxe e de subjetividade, por intermédio, especialmente, do controle que exerce sobre a mídia, a publicidade, as sondagens etc." (GUATTARI, 2001, p. 31). O objeto do Capitalismo Mundial Integrado é, hoje, "num só bloco: produtivo-econômico-subjetivo".

A subjetividade capitalística

[...] está manufaturada de modo a premunir a existência contra toda intrusão de acontecimentos suscetíveis de atrapalhar e perturbar a opinião. Para esse tipo de subjetividade, toda singularidade deveria ou ser evitada, ou passar pelo crivo de aparelhos e quadros de referência especializados. Assim, a subjetividade capitalística se esforça por gerar o mundo da infância, da loucura, da dor, da morte, do sentimento de estar perdido no cosmos... É a partir dos dados existenciais mais pessoais - deveríamos dizer mesmo infra-pessoais - que o CMI constitui seus agregados subjetivos maciços, agarrados à raça, à nação, ao corpo profissional, à competição esportiva, à virilidade dominadora, à star da mídia... (GUATTARI, 2001, p. 33-34)

Para Guattari e Rolnik (1996), essa tentativa de controle social por meio da produção da subjetividade em escala planetária, choca-se com fatores de resistência, com processos de diferenciação permanente. Movimentos que não apenas resistem ao processo de serialização da subjetividade, mas, também, produzem modos de subjetividade originais e singulares.

O termo singularização designa os processos disruptores no campo da produção do desejo: trata-se dos movimentos de protesto do inconsciente contra a subjetividade capitalística, por meio da afirmação de outras maneiras de ser, outras sensibilidades, outra percepção etc. Guattari (2001) chama a atenção para a importância política de tais processos, entre os quais se situariam os movimentos sociais, as minorias - enfim, os desvios de toda espécie.

Guattari (2001, p. 28) propõe que, em cada foco existencial parcial, as práxis ecológicas busquem "detectar os vetores potenciais de subjetivação e de singularização".

Nossas investigações envolvem essa problemática: escapar à subjetividade serializada, instalar minoridades para que possam ser traçadas linhas de fuga, de modo que o desejo escape dessa tentativa de modelagem. Escapar aos moldes, aos modelos, às formas preestabelecidas, evidenciando a potência da invenção. Aprender com Efigênia. 
As três ecologias se desprendem dos paradigmas pseudocientíficos, operando com "uma lógica diferente daquela que rege a comunicação ordinária entre locutores e auditores e, simultaneamente, diferente da lógica que rege a inteligibilidade dos conjuntos discursivos e o encaixe indefinido dos campos de significação" (GUATTARI, 2001, p. 27). Trata-se da lógica das intensidades, ou eco-lógica; lógica processual, cujo modo de operar está próximo daquele do artista.

\section{Cartografia, pesquisa processual}

Tais processos podem ser cartografados. Assim, buscamos cartografar (ROLNIK, 2007) as marcas de nossos encontros com Efigênia. Observamos e registramos susm, inventando e abrindo mundos. a atuação na feira dominical de antiguidades e artesanato do Largo da Ordem, em Curitiba (figuras 1 e 2). Além de registros fotográficos, produzimos documentários da atuação de Efigênia na feira e do acervo mantido em sua residência (figuras 3 e 4). A produção audiovisual foi realizada entre os anos de 2006 e 2009, com a colaboração da professora de metodologia do ensino de artes visuais e fotógrafa Juliana Gisi.

Nos documentários, Efigênia narra as histórias de vários bonecos. Trabalhamos também com depoimentos de Efigênia produzidos em uma série de encontros que tivemos. Essas foram as principais fontes da pesquisa, que se estendeu até o ano de 2010. Além delas, trabalhamos com o documentário "O filme da rainha" (2005) e com a monografia que aborda aspectos de sua história de vida: "Efigênia: uma artista da sucata, um pé de chinelo", de Ana Carolina Trovão (2000).

A cartografia como procedimento de pesquisa envolve o ensaio do traçado de uma geografia de encontros. Criam-se formas de expressão para impactos sofridos por um território subjetivo, para produção de sentido, de pensamento com e a partir da experimentação. Cartografar tais movimentos implica uma prática que lhes dá visibilidade e sentido. Implica pensar os efeitos dos encontros enquanto eles acontecem e, também, seus rastros. Forma de pesquisa processual, afinada com seu objeto de investigação, quando esse objeto é processual, como os processos criativos e de formação da subjetividade.

Com Efigênia, acompanhamos a expressão singular de um movimento vital em que corpo, pensamento e criação estão emaranhados em um mesmo processo de subjetivação.

\section{Desformar}

Aprendi com Rômulo Quiroga (um pintor boliviano):

A expressão reta não sonha.

Não use o traço acostumado.

A força de um artista vem das suas derrotas.

Só a alma atormentada pode trazer para a voz um

formato de pássaro.

Arte não tem pensa:

O olho vê, a lembrança revê, e a imaginação transvê.

É preciso transver o mundo.

Isto seja: 
Deus deu a forma. Os artistas desformam.

É preciso desformar o mundo:

Tirar da natureza as naturalidades.

Fazer cavalo verde, por exemplo.

Fazer noiva camponesa voar - como em Chagall.

Agora é só puxar o alarme do silêncio que eu saio por aí a desformar.

Até já inventei mulher de 7 peitos para fazer vaginação comigo. (BARROS, 2000, p. 75)

É preciso desformar o mundo.

Talvez seja a imaginação que vê. Talvez ver seja uma potência mais da imaginação do que do órgão olho. Talvez a imaginação venha primeiro. Efigênia viu papéis de bala/pérolas no chão da rua. Em sua narrativa, foram essas pérolas que a levaram a inventar-se como "uma artista da sucata, um pé de chinelo". Se, naquela manhã, visse papéis de bala no chão da rua XV de Novembro, não haveria magia e criação. Talvez possamos pensar que olhamos, vemos e transvemos com a imaginação.

Efigênia desforma, transvê. Aprender com ela, deixando-nos contagiar por seus procedimentos, sua eco-lógica, lógica das intensidades. Efigênia, que fabrica seus próprios óculos, elementos indispensáveis em sua performance.

A produção de Efigênia evoca aquilo que o pintor francês Jean Dubuffet (1967) chamou de Art Brut. Conceito criado por ele, em torno de 1945, designando a arte feita por pessoas que estão fora de qualquer instituição ligada ao meio artístico. Dubuffet estudou e colecionou várias dessas produções, criando a Coleção que hoje tem um lugar próprio: a Collection de l'art brut, em Lausanne, na Suíça, aberta ao público a partir de 1976.

Figura 3. Escultura de Efigênia Rolim.

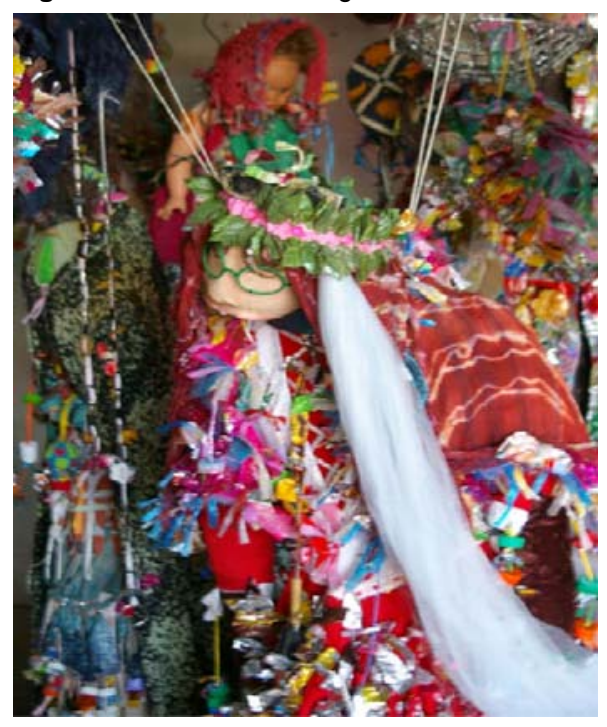

Foto: Juliana Gisi. 
Para Dubuffet (apud THÉVOZ, 2001), arte bruta é aquela praticada por pessoas que, por diversas razões, escaparam aos condicionantes culturais e ao conformismo social. Entre elas, solitários, inadaptados, internos de hospitais psiquiátricos, detentos, "marginais" de toda espécie. Desconhecendo as tradições artísticas - sem se preocupar com a crítica, com os cânones e os clichês da arte clássica e da arte da moda -, produzem obras altamente originais, em diversos aspectos: temas, materiais trabalhados, modos de escrita etc. (THÉVOZ, 2001, p. 7).

Em "Mille Plateaux", Deleuze e Guattari (1980) afirmam a respeito da arte bruta, que não se trata de algo patológico ou primitivo, mas de liberação de matérias de expressão.

A noção de arte bruta distingue essa criação daquela conhecida como arte naïf. A arte bruta difere-se da naïf, pelo menos em dois aspectos: o artista brut não visa o reconhecimento pela cultura instituída e, também, não se utiliza de técnicas consagradas. Ao contrário, é um bricoleiro: de qualquer coisa, faz uma matéria de expressão (KASPER, 2006).

O contato com o Museu de l'Art Brut, em Lausanne, provoca a impressão de que "aqueles artistas usaram qualquer coisa que estava à mão para criar uma outra coisa, manifestando toda a potência inventiva da bricolagem" (KASPER, 2006, p. 204).

Efigênia bricoleira, que contrói, ao mesmo tempo, sua vida e seu trabalho com elementos os mais heterogêneos.

Não pretendemos classificar ou definir a produção de Efigênia como arte bruta, mas buscamos ressonâncias com obras apresentadas como arte bruta, para pensarmos sua produção. Interessa-nos seu procedimento bricoleiro.

Como aprender com esse procedimento? Como tornar-se também bricoleira, nessa didática da invenção, criar novas possibilidades de vida? Efigênia conseguiu se estabelecer em um lugar - uma feira de antiguidades e artesanato, sendo que o seu trabalho teria pouquíssima relação com o artesanato, enquanto uma técnica tradicional - que lhe propicia uma forma de contato com o público, os transeuntes. Ali ocorre a animação de seus bonecos, a invenção de narrativas envolvendo uma complexa performance. Em um processo de subjetivação sem fim, ela mesma construiu a Efigênia da feira, compondo com os figurinos criados com fragmentos de embalagens plásticas, tecidos, papéis de bala e inúmeros materiais abandonados pelo consumo.

Dentre os materiais, chama a atenção o uso de embalagens, outrora roupagens de mercadorias, agora retomadas e transmutadas em matéria de expressão.

Efigênia apresentava-se mesmo sem que as pessoas comprassem seus bonecos e mantos; bastava aproximarem-se. Talvez o que mais importa seja esse dispositivo criado em meio aos transeuntes da feira: potencializar situações de contato.

De que falam ou o que fazem falar essas narrativas? Compõem com elementos míticos, profecias, fragmentos do cotidiano, acontecimentos históricos, cuidados com o meio ambiente, encontro entre etnias, entre espécies diversas, educação dos filhos, relações com a alteridade.

Algumas delas têm uma moral. Efigênia oferecia algumas lições para seu público. Certa vez, finalizando uma apresentação com bonecos, na qual uma mãe dava um apito para o filho, ela concluiu: "A bistória dela é o seguinte: você ensinar para teu filho o caminho. Você não pode passar na frente... Você tem que cuidar dele, mas tem que por ele na frente."

${ }^{2}$ Diário de Campo, 2006. 
E continuou:

Enquanto é criança eu vou. Depois que virou adolescente, que já tem cabeça, já fez seu primeiro grau, então deixe que ele vai, porque se você começa a definir, acaba tirando a vocação dele. Porque você vai escolher pra ele o que ele tem que ser, ele fica muito inseguro. Então, filho a gente nunca deve ensinar o caminho passando na frente, tem que acompanhar.

Em 2006, na feira do Largo da Ordem, mostrou-me suas novas bonecas, contou histórias de sua vida e histórias da vida de uma boneca, de modo que as duas estavam conectadas. Contou-me que "caiu no conto do cheque". Em uma agência bancária, foi abordada por duas pessoas bem vestidas, que se ofereceram para segurar sua bolsa e desapareceram, levando dinheiro, documentos e agenda. Efigênia ficou muito impressionada e assustada com o ocorrido. Afirmava que isso aconteceu com ela por ter se tornado uma pessoa com certa fama, conhecida. Ser famosa traz consigo esse problema - afirmou Efigênia - porque as pessoas pensam que você tem dinheiro. A partir disso que lhe aconteceu, ela fez uma boneca de papel de bala e outras embalagens, com um tórax de boneca de plástico. Ela vinha acoplada a um carrinho (Meio humana, meio máquina?). Seu tórax era todo furado, boneca com corpo perfurado por balas. Ela contava assim:

Esse boneco é o palhaço. Essa boneca é uma modelo, o nome dela é Flor Hippie. Teve uma briga para entrar no circo porque o palhaço vendeu mais ingresso do que cabia e as pessoas queriam entrar pra ver a modelo. Então aconteceu uma briga e a modelo levou vários tiros. Então as pessoas perguntaram:

- O que adianta a fama?

Morrer no palco.

- Por que fama? Fama é morrer no palco?

O palhaço pegou a modelo, mandou embalsamar e carrega metade do corpo dela. ${ }^{3}$

Depois Efigênia jogou o foco para outro boneco: o palhaço. Reproduziu uma história recorrente no mundo dos palhaços (de circo ou de teatro): enquanto estava em cena, atuando, chegou-lhe a notícia da morte de alguém de sua família. Mas o espetáculo não podia parar diante de uma desgraça. Assim como o palhaço, Efigênia também não pôde chorar em público quando foi roubada na agência bancária.

Arte e vida emaranhados, enovelados.

Com papéis de bala e outros objetos - com lixo? - , Efigênia faz bonecos. Aliada a eles, apresenta uma performance especial, pois cada boneco tem uma história própria. $\mathrm{Na}$ construção do boneco vemos, muitas vezes, emaranhar-se fragmentos da história de vida da própria Efigênia. Como se o movimento de criação dos bonecos envolvesse, também, um reinventar-se de Efigênia, na construção dessas narrativas. Fragmentos de histórias, de profe-

${ }^{3}$ Diário de Campo, 2006. 
Kasper, K. M.

cias, de papéis de bala, de tecidos e outros materiais compõem algo inédito. Ela contará cada história de modo singular, com incrível senso cênico, aprisionando o ouvinte, capturando seu olhar. Momento no qual os bonecos e Efigênia nos contam, falam-nos de várias coisas: desde como eles foram criados, suas histórias, e o que têm a trazer para nosso mundo. Ou como desformá-lo.

Quando alguém se aproximava da banca de Efigênia na feira e lhe interrogava a respeito de suas criações, é possível que se produzisse o seguinte efeito: Efigênia e seus bonecos apresentavam uma performance muito especial. Como se ela realmente apresentasse um espetáculo - único a cada vez - para expor suas obras ao público interessado. Essa performance envolvia um agenciamento muito peculiar: entrelaçamento entre as formas plásticas, as narrativas das quais emergiam e a performance singular, criada no contato com aquele público.

Esse encontro com Efigênia sugere, para a Educação, uma abertura à experimentação. Sugere, para o discurso da educação ambiental, a possibilidade do abandono de objetivos que visam substituir um modelo socioambiental por outro, substituir um comportamento individualista por "um altruísmo virtuoso, para avançar a vivências que possam colocar o sujeito em contato com o gérmen do novo, quebrando, assim, condicionantes de uma vida inteiramente ditada pelas condições já postas" (MARIN; AVANSO; SILVEIRA, 2011, p. 284). Formação e educação para além de modelos e de caminhos normativos e prescritivos para sua realização.

Com Efigênia aprendemos que inventar é resistir às formas dominantes de um mundo que se quer homogêneo e povoado de "subjetividades para o consumo" (GODOY, 2007 a, p. 6). Ela implode esse mundo, instaurando outros, heterogêneos, nos modos como afeta e é afetada pelas forças do ambiente, transformando-as em arte, em vida-criação. Efigênia nos ensina também que, além da preservação, de um "discurso conservacionista e um pensamento da conservação, ambos pautados em práticas consideradas saudáveis e comportamentos considerados adequados" (GODOY, 2007b, p. 201), podem-se construir novas "linhas de uma aprendizagem experimental, que remetem, sobretudo, àquilo que permanece indomesticável: as ecologias que a vida inventa, menores ecologias” (GODOY, 2007b, p. 201).

Do ponto de vista da ecosofia, podemos pensar a arte como potência. Nesse sentido, não se trata de transmissão de mensagens ou criar novos padrões, mas "cabe especialmente à função poética recompor universos de subjetivação", "catalisar operadores existenciais suscetíveis de adquirir consistência e persistência" (GUATTARI, 1992, p. 31). Potência capaz de nos retirar dos lugares costumeiros, nos desestabilizar, desautomatizar, abrir-nos a novas sensações, novos modos de sentir, pensar e agir.

"É nas trincheiras das artes que se encontram os núcleos de resistência dos mais consequentes ao rolo compressor da subjetividade capitalística, a da unidimensionalidade, do equivaler generalizado, da segregação, da surdez para a verdadeira alteridade" (GUATTARI, 1992, p. 115). Ele não se refere somente aos artistas "patenteados", mas à existência "de toda uma criatividade subjetiva que atravessa os povos e as gerações oprimidas, os guetos, as minorias...” (GUATTARI, 1992, p. 115). Daí sua importância também quando se pensa em outras possibilidades, de vida, de educação, em "diversas perspectivas ecológicas de educações, indefinitivas, singulares e múltiplas” (BARCHI, 2009, p. 191).

Conforme Félix Guattari (1992, p. 115), 
[...] a ecologia generalizada - ou ecosofia - agirá como ciência dos ecossistemas, como objeto de regeneração política, mas também como engajamento ético, estético, analítico, na iminência de criar novos sistemas de valorização, um novo gosto pela vida, uma nova suavidade entre os sexos, as faixas etárias, as etnias, as raças...

Desformar o mundo, abrir possibilidades outras para se pensarem os processos de formação e subjetivação como experimentações vitais. Invenção de uma vida.

Figura 4. Escultura de Efigênia Rolim.

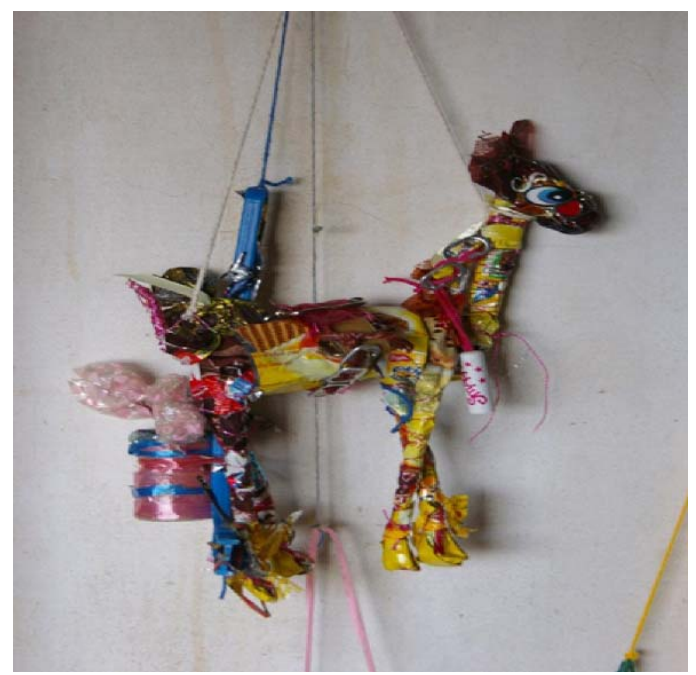

Foto: Juliana Gisi.

\section{Referências}

ALBERNAZ, R.; LAURINO, D. Formação ecosófica: tramas entre a formação e a educação ambiental. Revista Eletrônica do Mestrado em Educação Ambiental, Rio Grande, v. 27, p. 34-45, jul./dez. 2011.

BARCHI, R. Contribuições "inversas", "perversas” e menores às educações ambientais. Interacções, Lisboa, v. 5, n. 11. p. 174-192. 2009. Disponível em: < http://revistas.rcaap.pt/interaccoes/article/view/ 381>. Acesso em: 12 maio 2014.

BARROS, M. de. Livro sobre nada. Rio de Janeiro: Record, 2000.

BENFICA, G. Os desafios da ecosofia de Guattari para a educação ambiental. Revista da FAEEBA, Salvador, v. 16, n. 28, p. 91-104, 2007.

CUNHA, M. M. da S. Educação ambiental e nordestinidade: desafios à práxis ecologista. Revista Brasileira de Educação Ambiental, Rio Grande, v. 7, n. 2, p. 10-17, 2012. Disponível em: <http:/ / www.seer.furg.br/revbea/article/view/1809>. Acesso em: 12 maio 2014.

DELEUZE, G.; GUATTARI, F. Mille plateaux. Paris: Minuit, 1980. 
Kasper, K. M.

DUBUfFET, J. Prospectus et tous écrits suivants. Paris: Gallimard, 1967.

GODOY, A. Educação, meio-ambiente e subjetividade na sociedade de controle: por uma ética dos afectos. Interacções, Lisboa, v. 5, n. 11. p. 8-28. 2009.

. Experimentações estético-políticas: do corpo condenado ao corpo liberado, a vida como matéria ética. Alegrar, Campinas, v. 4, 2007a. Disponível em: <http://www.alegrar.com.br/04/ textos_A_04/05_materia.pdf>. Acesso em: 07 out. 2013.

. Nas bordas do mar: esboço de uma aprendizagem experimental [como desfazer uma educação ambiental]. Verve, São Paulo, v. 11, p. 183-201, 2007b.

GODOY, A.; AVELINO, N. Educação, meio ambiente e cultura: alquimias do conhecimento na sociedade de controle. Educação em Revista, Belo Horizonte, v. 25, n. 3, p. 327-351, dec. 2009.

GUATTARI, F. Caosmose: um novo paradigma estético. São Paulo: Ed. 34, 1992.

. As três ecologias. 11. ed. Campinas: Papirus, 2001.

GUATTARI, F.; ROLNIK, S. Micropolítica: cartografias do desejo. 4. ed. Petrópolis: Vozes, 1996.

KASPER, C. P. Habitar a rua. 2006. 250 f. Tese (Doutorado em Ciências Sociais) - Instituto de Filosofia e Ciências Humanas, Universidade Estadual de Campinas, Campinas, 2006.

KASPER, K. M. Efigênia e a potência da vida. Alegrar, Campinas, 2007. Disponível em: < http: www.alegrar.com.br/03/textos_alegrar_03/7_Efigenia.pdf>. Acesso em: 07 out. 2013.

MARIN, A. A.; AVANSO, C.; SILVEIRA, E. Experiências de "indeterminação": artistas falando a educadores. OPSIS, Catalão, v. 11, n. 1, p. 271-286, jan./jun. 2011.

O FILME DA RAINHA: documentário sobre Efigênia Ramos Rolim. Direção: S. Mercúrio. Curitiba: 2005.

REIGOTA, M. Educação ambiental brasileira: a contribuição da nova geração de pesquisadores e pesquisadoras. Interacções, Lisboa, v. 5, n. 11. p. 1-7. 2009.

ROLNIK, S. Cartografia sentimental: transformações contemporâneas do desejo. 2. ed. Porto Alegre: Sulina: Ed. UFRGS, 2007.

THÉVOZ, M. Collection de l'art brut. Lausanne: Institut Suisse pour l'étude de l'art: BNP Paribas Suisse, 2001.

TROVÃO, A. C. R. Efigênia: uma artista da sucata, um pé de chinelo. 2000. Trabalho de Conclusão de Curso (Graduação em Ciências Sociais) - Universidade Federal do Paraná, Curitiba, 2000.

Artigo recebido em 13/11/13. Aceito em 04/03/14. 